\title{
Influence of Male Age and Diet on Reproductive Potential of Orius laevigatus (Hemiptera: Anthocoridae)
}

\author{
MAARTEN BONTE AND PATRICK DE CLERCQ ${ }^{1}$ \\ Laboratory of Agrozoology, Department of Crop Protection, Ghent University, Coupure Links 653, \\ B-9000 Ghent, Belgium
}

\begin{abstract}
Ann. Entomol. Soc. Am. 103(4): 597-602 (2010); DOI: 10.1603/AN09180
ABSTRACT When assessing the reproductive potential of laboratory-reared predatory insects, the role of males is often neglected, although they may have a significant impact on the reproductive output of their female mates. The current study investigated the effect of age and diet of males on the reproductive capacity of the anthocorid predator Orius laevigatus (Fieber) (Hemiptera: Anthocoridae). The tested diets consisted of eggs of Anagasta kuehniella (Zeller) and an egg yolk-based artificial diet. Regardless of their diet, virgin females did not produce any mature oocytes, indicating that mating is required to complete ovarian development. Food source and age of the males affected the reproductive potential of their female mates. When both males and females were offered the artificial diet, male age had a significant effect on female oocyte counts. Virgin females that were mated with 0 -d-old virgin males produced fewer offspring than those mated with 8-d-old virgin males. In contrast, male age did not affect fecundity when the males were fed A. kuehniella eggs. The implications of the findings for the mass production of $O$. laevigatus are discussed.
\end{abstract}

KEY WORDS Orius laevigatus, artificial diet, reproduction, mating, biological control

Augmentative biological control of agricultural pests is still less practiced than chemical control, despite its marked growth since the first commercialization of arthropod natural enemies in the late 1960s. The slow adoption rate of biological control is in part related to problems associated with the production and distribution of parasitoids and predators leading to high market prices (Bale et al. 2008). As a result, numerous studies (see Riddick 2009) were carried out on insect rearing systems with the bigger aim of reducing production costs for biological control agents. The focus of these studies was mainly on the development of cheap factitious and artificial foods as a replacement for the often more expensive natural foods that are still commonly used in commercial insectaries. The suitability of a diet is assessed by evaluating the developmental and reproductive performance of the produced insects. Quality control criteria for developmental, reproductive, and mobility traits of laboratory produced biological control agents have been proposed by the International Organization for Biological Control (i.e., the IOBC Quality Control Guidelines, van Lenteren et al. 2003). Lifetime fecundity has often been used as a parameter to assess the quality of a natural enemy agent as a function of diet (Grenier and De Clercq 2003), because a high fecundity will speed up its establishment in the crop.

\footnotetext{
${ }^{1}$ Corresponding author, e-mail: patrick.declercq@ugent.be.
}

The role of females in rearing systems for insect predators has received much more attention than that of males, because in many predators one male can fertilize several females. As a consequence, when developing diets for predators, the focus is primarily on females and males are often neglected. Nevertheless, it is widely recognized that in insects, males do affect offspring production by females. The effects of mating on female reproductive fitness can be categorized in three classes: the act of mating per se, presence of sperm, and transfer of accessory substances (Arnqvist and Nilsson 2000). Mating in itself may have positive and negative effects. It has several ecological and biological costs but it also can stimulate female egg production (Opp and Prokopy 1986, Rowe 1994, Watson et al. 1998). The presence of sperm can, in some insect species, stimulate and in others inhibit egg production and female fertility (Nilakhe 1977, Gromko et al. 1984). The accessory substances that are transferred to the females together with the sperm can have numerous complex positive and negative effects in insects. Seminal fluids can serve as nutrients, influence reproductive processes and protect females and their eggs from predation (Klowden 1999, Sirot et al. 2006). These substances are produced by the accessory reproductive glands of males and contain carbohydrates, lipids, amino acids, and amines and sometimes unexpected species-specific materials such as uric acid, prostaglandins, juvenile hormones, and toxins (Gilliott 2003). Some of the transferred peptides, 
such as the insect angiotensin-converting enzyme, can affect the mating behavior of the female or may influence the activity of the female oviduct (Tram and Wolfner 1998). Yoshii et al. (2001) showed that some of the components of insect diets such as hen's egg yolk may affect the function of those peptides.

The role of males in Orius spp. was studied by Mendes et al. (2003) and Leon-Beck and Coll (2009). Both studies concluded that virgin females of Orius sp. do not lay eggs. Leon-Beck and Coll (2009) found that females of Orius laevigatus (Fieber) are monandrous; once females have mated, they avoid any additional mating. In contrast, males seem to be polygamous. Leon-Beck and Coll (2009) also reported that the female to mate first with a male deposits more eggs than the following females.

Orius laevigatus (Fieber) (Hemiptera: Anthocoridae) is a biological control agent of thrips, spider mites, aphids, and whiteflies and has been commercially available since the 1990s (Chambers et al. 1993, Montserrat et al. 2000, Venzon et al. 2002). Commercial mass production of this predator is generally done using eggs of the Mediterranean flour moth, Anagasta kuehniella (Zeller), as food and plant materials such as bean pods as oviposition substrates. Several studies have focused on the development of more cost-effective, factitious foods and artificial diets for this anthocorid predator (Arijs and De Clercq 2004, De Clercq et al. 2005, Bonte and De Clercq 2008). The current study aimed at evaluating the influence of diet and age of male mates on the reproductive fitness of $O$. laevigatus females.

\section{Materials and Methods}

Predator Colony. A culture of $O$. laevigatus was initiated with insects originally acquired from Biobest N.V. (Westerlo, Belgium). The insects were reared on A. kuehniella eggs and pollen and offered a sharp pepper, Capsicum annum L. 'Cayenne Long Slim' plant as a source of moisture and an oviposition substrate. The colony was kept in a growth chamber at $23^{\circ} \mathrm{C}, 65 \pm 5 \% \mathrm{RH}$, and a photoperiod of 16:8 (L:D) h.

Diets. In all experiments, the predator was offered either a factitious food or an artificial diet. The factitious food consisted of eggs of A. kuehniella, which were supplied in frozen form by Koppert B.V. (Berkel en Rodenrijs, The Netherlands). The flour moth eggs were replenished every other day. The artificial diet was a meridic diet developed for O. laevigatus by Arijs and De Clercq (2002). This diet contained $3 \mathrm{~g}$ of casein, $2.5 \mathrm{~g}$ of casein hydrolysate, $2 \mathrm{~g}$ of soy hydrolysate, $3 \mathrm{~g}$ of lactalbumin, $30 \mathrm{~g}$ of fresh hen's egg yolk, $3 \mathrm{~g}$ of soy oil, $1 \mathrm{~g}$ of peanut oil, $1 \mathrm{~g}$ of dextrose, $0.5 \mathrm{~g}$ of Wesson's salt mix, $53.9 \mathrm{~g}$ of water, $0.06 \mathrm{~g}$ of a vitamin mix based on the vitamin composition of bovine liver (weight percentages: $25.4 \%$ nicotinic acid, $4.9 \%$ riboflavin, $0.5 \%$ thiamine, $1.5 \%$ vitamin $\mathrm{B}_{6}, 12.4 \% \mathrm{Ca}$-pantothenate, $1 \%$ folic acid, $0.1 \%$ biotin, and $54.2 \%$ vitamin $\mathrm{C}$ ), and $1 \mathrm{mg}$ of vitamin $\mathrm{E}$. The diet was kept at $4^{\circ} \mathrm{C}$ for a maximum of $7 \mathrm{~d}$ and encapsulated using an encapsulation device (USDA-ARS, Gainesville, FL) into hemispherical domes $(70 \mu \mathrm{l})$ consisting of stretched Parafilm $\mathbf{M}$ as described by Bonte and De Clercq (2008). The artificial diet was replaced daily.

Experiments. Adults of $O$. laevigatus used in the mating experiments had been reared as immatures on either diet. For treatments with the artificial diet, first instars $(<24 \mathrm{~h}$ old) of the predator were individually isolated in plastic containers $(5 \mathrm{~cm}$ in diameter, $2 \mathrm{~cm}$ in height), provided with a Parafilm dome with diet and a dome with tap water and allowed to develop to adulthood. For treatments with A. kuehniella eggs, fourth instars of $O$. laevigatus were taken from the stock colony and isolated into similar plastic containers to preclude cannibalism in the late nymphal stage and to prevent mating upon adult emergence. In all experiments, only virgin males and females were used.

In a first experiment, the effect of diet on the reproductive potential of unmated females was tested. Freshly emerged females were offered the same food (A. kuehniella eggs or artificial diet) as in their nymphal stages and were isolated in a 5-cm-diameter plastic container without a male. Nymphal survival and development of female nymphs fed artificial diet were monitored daily. Female adults were weighed on a Sartorius Genius ME215P balance (Sartorius, Goettingen, Germany) upon adult emergence ( $<24 \mathrm{~h}$ old). After $8 \mathrm{~d}$ all females were dissected according to the method described by Bonte and De Clercq (2008) and oocytes were scored as a prediction of the reproductive capacity of the predator. All oocytes within the ovaries and oviducts were scored as follows: 1, late vitellogenic to mature oocyte; 0.5 , early to mid vitellogenic oocyte, i.e., having minimum half the size of a mature oocyte; 0.25 , previtellogenic oocyte, i.e., smaller than half the size of a mature oocyte; and 0 , no observable oocyte. The scores of oocytes in the ovaries and oviducts were totalled up for each female to yield oocyte counts.

A second experiment assessed the influence of male age and diet on the reproductive potential of females. All females were fed artificial diet throughout their nymphal development and adult life. Newly emerged virgin females were paired with 0 -, 5- or 8-d-old virgin males that were fed either artificial diet or A. kuehniella eggs during their nymphal and adult life. Females were monitored, weighed, and dissected as described above. Male adults were weighed just before being placed together with a female.

In a third experiment, the influence of male age and male diet on the oviposition of females was investigated. All females were offered artificial diet during their nymphal and adult life. Upon emergence, virgin females were placed together with a virgin male in a Plexiglas container (9 $\mathrm{cm}$ in diameter, $4 \mathrm{~cm}$ in height) holding a C. annuum Cayenne Long Slim leaf, with its petiole placed in water as an oviposition substrate. Males were either $0 \mathrm{~d}$ old and reared on artificial diet as nymphs and adults or 0 or $8 \mathrm{~d}$ old and reared on $A$. kuehniella eggs. Females and males were monitored and weighed as described above. Oviposition and egg hatch were monitored during the first $25 \mathrm{~d}$ of female 
Table 1. Effect of diet on developmental time, adult weight, and oocyte counts of unmated $\boldsymbol{O}$. laevigatus females

\begin{tabular}{ccccc}
\hline \hline \multirow{2}{*}{ Diet } & $n^{a}$ & \multicolumn{2}{c}{ Female } & Developmental \\
\cline { 3 - 4 } & & $\begin{array}{c}\text { Adult wt } \\
(\mathrm{mg})\end{array}$ & $\begin{array}{c}\text { Oocyte count (no. } \\
\text { oocytes /female) }\end{array}$ \\
\hline A. kuehniella & 14 & $12.7 \pm 0.1 \mathrm{~d}$ & $0.50 \pm 0.05 \mathrm{a}$ & $2.0 \pm 0.3 \mathrm{a}$ \\
Artificial diet & 18 & $15.1 \pm 1.4 \mathrm{~b}$ & $0.36 \pm 0.03 \mathrm{~b}$ & $1.7 \pm 1.5 \mathrm{a}$ \\
\hline
\end{tabular}

Means $\pm \mathrm{SE}$ within a column followed by the same letter are not significantly different $(P>0.05$; Student's $t$-test).

${ }_{a}^{a}$ Number of females tested per treatment.

adult life. C. annum Cayenne Long Slim were checked daily to determine preoviposition period.

Statistical Analysis. A one-way analysis of variance (ANOVA) was performed on the parameters developmental time, adult weight, preoviposition period, number of eggs oviposited after $25 \mathrm{~d}$, and egg hatch; means were separated using Tamhane or Tukey tests $(P=0.05)$ in cases of unequal or equal variances, respectively. Percentages of egg hatch were transformed using a square-root transformation before analysis. Developmental time, adult weight of females fed artificial diet, and oocyte counts in the first experiment were analyzed using a Student's $t$-test. A Kruskal-Wallis one-way ANOVA was carried out to determine differences in oocyte counts, and means were separated using a Mann-Whitney $U$ test with Bonferroni correction (SPSS Inc. 2003). A two-way ANOVA was conducted to evaluate whether diet had a different effect on adult male weight and oocyte counts of females when males were 0,5 , or $8 \mathrm{~d}$ old.

\section{Results}

In the first experiment, developmental time $(t=$ $-10.087, \mathrm{df}=63.173, P<0.001)$ and adult weight $(t=$ 15.533, df $=87.533, P<0.001)$ of females fed $A$. kuehniella eggs were superior to those of females that had developed on artificial diet (Table 1). Virgin females produced, irrespective of diet $(t=0.944$, df $=$ $30, P=0.353)$, no mature or vitellogenic oocytes during the first $8 \mathrm{~d}$ of their adult life, but some previtellogenic and early vitellogenic oocytes were observed.

A two-way ANOVA showed a significant interaction effect between male age and diet on oocyte counts in the second experiment (Table 2), indicating that diet of males influenced the effect of male age on oocyte counts. Both main effects had a significant impact on male weight. Males reared on A. kuehniella eggs were heavier than those reared on artificial diet, and 5-d-old males were heavier than 0 -d-old males. Significant differences were found for male adult weight $(F=$ 25.645; $\mathrm{df}=5,90 ; P<0.001)$ and oocyte counts $\left(\chi^{2}=\right.$ 26.432 , df $=5, P<0.001$ ) (Table 3 ). The age of males reared on artificial diet had a significant influence on the oocyte counts of females fed on artificial diet. Females mated with 8-d-old males reared on artificial diet had more than double the number of oocytes of those mated with 0 -d-old diet-reared males. However,
Table 2. Two way-ANOVA results indicating the effect of age and diet on male weight and female oocyte counts of $\boldsymbol{O}$. laevigatus

\begin{tabular}{lcc}
\hline \hline Source & Adult male wt & $\begin{array}{c}\text { Oocyte count (no. } \\
\text { oocytes/female) }\end{array}$ \\
\hline Age & 2 & 2 \\
df & 4.877 & 9.495 \\
$F$ value & 0.01 & $<0.001$ \\
$P$ & & 1 \\
Diet & 1 & 3.981 \\
df & 115.562 & 0.049 \\
$F$ value & $<0.001$ & 2 \\
$p$ & 2 & 4.365 \\
Age $\times$ diet & 1.937 & 0.015 \\
df & 0.15 & 97 \\
$F$ value & & \\
$p$ & 90 & \\
Error term & & \\
df & & \\
\hline
\end{tabular}

male age had no significant impact on the oocyte counts of the females when the males were offered $A$. kuehniella eggs. The reproductive potential of the females was not significantly affected by diet of the males although oocyte counts of females mated with a 0 -d-old male reared on A. kuehniella eggs were almost double those of females mated with a newly emerged male that had developed on the artificial diet.

In the final experiment, preoviposition period $(F=$ $2.392 ; \mathrm{df}=2,42 ; P=0.104)$, number of eggs oviposited in $25 \mathrm{~d}(F=2.717 ; \mathrm{df}=2,57 ; P=0.075)$, and egg hatch $(F=2.777 ; \mathrm{df}=2,41 ; P=0.074)$ were not significantly influenced by age or diet of the males (Table 4). Adult weight of males was, however, significantly influenced by their $\operatorname{diet}(F=5.601 ; \mathrm{df}=2,57 ; P=0.006)$. Again, males reared on A. kuehniella eggs (0.38 mg) were significantly heavier than those that had developed on artificial diet $(0.33 \mathrm{mg})$.

\section{Discussion}

Virgin females fed A. kuehniella eggs or artificial diet were unable to produce any vitellogenic or mature oocytes. This is consistent with the findings of LeonBeck and Coll (2009) that unmated females of $O$. laevigatus did not oviposit. Ito and Nakata (1998) also stated that unmated females of Orius sauteri (Poppius) and Orius minutus (L.) failed to lay eggs and that these females showed no ovarian development. In our study, however, ovaries of virgin O. laevigatus females did show some early development. This suggests that O. laevigatus females require mating to mature their eggs. In contrast, unmated females of the predatory mirid Macrolophus pygmaeus (Rambur) and the predatory pentatomid Podisus maculiventris (Say) are able to complete ovarian development and deposit a reduced number of sterile eggs (De Clercq and Degheele 1997, Vandekerkhove et al. 2006).

Age and feeding status of male mates may affect the reproductive output of females. Females mated with young virgin males produced fewer offspring than those mated with older virgin males, when males were fed on artificial diet but did not when males were reared on A. kuehniella eggs. For some Orius spp., male 
Table 3. Effect of male age and diet on adult weight of males and oocyte counts of $O$. laevigatus females reared on artificial diet ${ }^{a}$

\begin{tabular}{|c|c|c|c|c|c|c|c|}
\hline \multicolumn{3}{|c|}{ Female } & \multicolumn{3}{|c|}{ Male } & \multirow[b]{2}{*}{$n^{b}$} & \multirow{2}{*}{$\begin{array}{c}\text { Oocyte count (no. } \\
\text { oocytes/female) }\end{array}$} \\
\hline Diet & $\begin{array}{l}\text { Developmental } \\
\text { time }(\mathrm{d})\end{array}$ & $\begin{array}{l}\text { Adult wt } \\
(\mathrm{mg})\end{array}$ & Diet & Age (d) & $\begin{array}{l}\text { Adult wt } \\
(\mathrm{mg})\end{array}$ & & \\
\hline \multirow[t]{6}{*}{ Artificial diet } & $15.7 \pm 0.08$ & $0.35 \pm 0.004$ & Artificial diet & 0 & $0.29 \pm 0.009 b$ & 20 & $5.1 \pm 1.0 \mathrm{~b}$ \\
\hline & & & & 5 & $0.29 \pm 0.006 b$ & 8 & $10.0 \pm 2.1 \mathrm{ab}$ \\
\hline & & & & 8 & $0.33 \pm 0.01 b$ & 20 & $12.5 \pm 0.8 \mathrm{a}$ \\
\hline & & & A. kuehniella & 0 & $0.39 \pm 0.01 \mathrm{a}$ & 20 & $9.6 \pm 1.4 \mathrm{ab}$ \\
\hline & & & & 5 & $0.41 \pm 0.01 \mathrm{a}$ & 19 & $13.2 \pm 0.9 \mathrm{a}$ \\
\hline & & & & 8 & $0.41 \pm 0.005 a$ & 18 & $10.8 \pm 1.0 \mathrm{a}$ \\
\hline
\end{tabular}

Means \pm SE within a column followed by the same letter are not significantly different $(P>0.05$; Tamhane's test [male adult weight] or Mann-Whitney $U$ test [weighted sum of oocytes]).

${ }^{a}$ All predators were offered the same diet during their nymphal and adult stages.

${ }^{b}$ Number of couples tested per treatment.

adults emerge earlier than females, particularly at lower temperatures (Musolin et al. 2004, Musolin and Ito 2008). Faster development of males might have an ecological significance: at the time females emerge, males are ready to mate with them (Musolin and Ito 2008). This strategy is defined as temperature-regulated protandry (Boyd and Alverson 2004). This trend disappears at higher temperatures, with females developing as fast as males. Consequently, at high temperatures males may not have fully matured at the time when females emerge. García-González and Simmons (2005) found that young males of the cricket Teleogryllus oceanicus (Le Guillou) had a greater proportion of nonviable sperm than older males. Gromko et al. (1984) stated that the presence of viable sperm in the female reproductive tract of the fruit fly Drosophila melanogaster (Meigen) stimulates egg production. Because older males possess more viable sperm, they may have thus a positive influence on the number of eggs oviposited by the female. The number of contractions of the male reproductive tract of 0 -d-old males of the earwig Euborellia annulipes (Lucas) was considerably lower that that of 8-d-old males. Contractions of the male reproductive tract move the seminal fluid along the reproductive system (Rankin et al. 2009).

The age and diet of the males had no effect on hatching rate of the eggs, indicating that these factors have no influence on the quality of sperm. These findings are in line with De Clercq et al. (2005) and Bonte and De Clercq (2008) who reported that the diet offered to O. laevigatus pairs did not affect hatching rate of deposited eggs.
After the first mating, female O. laevigatus avoid any additional matings, indicating that female $O$. laevigatus are in fact monandrous (Leon-Beck and Coll 2009). In addition, males start to mate immediately after adult emergence (Tawfik and Ata 1973). This emphasizes the importance of the first mating for females. In mass rearing systems using suboptimal foods such as artificial diets, this may imply that allowing newly emerged males to mate with females may prevent those females from having further more successful matings, which may eventually lead to a decline in production capacity. Therefore, it may be advisable to place female adults together with sufficient amounts of older males, particularly in artificial rearing systems. Thus, the proportion of older males should best exceed that of newly emerged males, increasing the chance for a female to mate with an older male. However, male fertility may decrease as the male ages (Price and Hansen 1998, Jones and Elgar 2004), but further investigation is needed to determine whether and at what age the fertility of male Orius starts to decline. This would lead toward a slightly male-biased sex ratio in mass rearing systems for $O$. laevigatus, which is in line with the recommendations of Leon-Beck and Coll (2009). They, however, suggested removing all males from the rearing system within 2-3 d after male emergence, because females maintained with males during their oviposition period had lower fecundities than those that were kept without males for the remaining oviposition period.

More research is needed to fully understand the impact of mating status of males on female reproduction. In the current study, only virgin males were used.

Table 4. Effect of male age and diet on oviposition and egg hatch of $O$. laevigatus females fed artificial diet ${ }^{a}$

\begin{tabular}{|c|c|c|c|c|c|c|c|c|c|}
\hline \multicolumn{3}{|c|}{ Female } & \multicolumn{3}{|c|}{ Male } & \multirow[b]{2}{*}{$n^{b}$} & \multirow[b]{2}{*}{$\begin{array}{l}\text { Preoviposition } \\
\text { period }(\mathrm{d})\end{array}$} & \multirow{2}{*}{$\begin{array}{l}\text { No. oviposited } \\
\text { eggs in } 25 \mathrm{~d} \\
\text { (eggs/female) }\end{array}$} & \multirow[b]{2}{*}{$\begin{array}{l}\text { Egg hatch } \\
(\%)^{c}\end{array}$} \\
\hline Diet & $\begin{array}{l}\text { Developmental } \\
\text { time }(\mathrm{d})\end{array}$ & $\begin{array}{l}\text { Adult wt } \\
\text { (mg) }\end{array}$ & Diet & $\begin{array}{l}\text { Age } \\
(\mathrm{d})\end{array}$ & $\begin{array}{l}\text { Adult wt } \\
\text { (mg) }\end{array}$ & & & & \\
\hline Artificial diet & $16.5 \pm 0.1$ & $0.39 \pm 0.006$ & $\begin{array}{l}\text { Artificial diet } \\
\text { A. kuehniella } \\
\text { A. kuehniella }\end{array}$ & $\begin{array}{l}0 \\
0 \\
8\end{array}$ & $\begin{array}{l}0.33 \pm 0.008 \mathrm{~b} \\
0.38 \pm 0.01 \mathrm{a} \\
0.38 \pm 0.01 \mathrm{a}\end{array}$ & $\begin{array}{l}20 \\
20 \\
20\end{array}$ & $\begin{array}{l}6.5 \pm 0.8 \mathrm{a} \\
6.5 \pm 0.8 \mathrm{a} \\
4.9 \pm 0.4 \mathrm{a}\end{array}$ & $\begin{array}{l}43.5 \pm 9.6 \mathrm{a} \\
38.5 \pm 11.3 \mathrm{a} \\
71.2 \pm 11.1 \mathrm{a}\end{array}$ & $\begin{array}{l}78.3 \pm 4.6 \mathrm{a} \\
67.3 \pm 8.4 \mathrm{a} \\
83.3 \pm 2.1 \mathrm{a}\end{array}$ \\
\hline
\end{tabular}

Means $\pm \mathrm{SE}$ within a column followed by the same letter are not significantly different $(P>0.05$; Tukey's test [number of oviposited eggs in $25 \mathrm{~d}$ ] or Tamhane's test [male weight and preoviposition period]).

${ }^{a}$ All predators were offered the same diet during their nymphal and adult stages.

${ }^{b}$ Number of couples tested per treatment.

${ }^{c}$ Original data, transformed for analysis using $\sqrt{ } \mathrm{x}$. 
Leon-Beck and Coll (2009) showed that male mating history affected the reproductive output of $O$. laevigatus females. Their results indicated that male sperm is depleted after three copulations within the same day and is not replenished within $3 \mathrm{~d}$. Furthermore, in our laboratory experiment females were not allowed to choose their male mates. Under field conditions, females may reject less fit males, including incompletely matured males or males that have just mated. Females of several insect species such as the fruit flies D. melanogaster and Drosophila montana Stone, Griffen \& Patter; Colias butterflies; the fly Coelopa frigida (F.); and the cockroach Nauphoeta cinerea (Olivier) have been reported to gain benefit from selecting their male mate (Partridge 1980, Watt et al. 1986, Crocker and Day 1987, Moore 1994, Hoikkala et al. 1998). However, the mating status of the female also may affect male mating choice. Males of the hide beetle Dermestes maculatus De Geer, e.g., show a preference for virgin females and discriminate mated females (McNamara et al. 2004).

\section{Acknowledgment}

This research was supported by project B/06836/01 from Bijzonder Onderzoeksfonds-Universiteit Gent.

\section{References Cited}

Arijs, Y., and P. De Clercq. 2002. Artificial diets for the production of natural enemies (predators and parasitoids) of greenhouse pest insects. Final consolidated report, FAIR-project no. CT-98 4322

Arijs, Y., and P. De Clercq. 2004. Liver-based diets for the production of Orius laevigatus (Heteroptera: Anthocoridae). Biocontrol 49: 505-516.

Arnqvist, G., and T. Nilsson. 2000. The evolution of polyandry: multiple mating and female fitness in insects. Anim. Ecol. 60: 145-164.

Bale, J. S., J. C. van Lenteren, and F. Bigler. 2008. Biological control and sustainable food production. Philos. Trans. R. Soc. B 363: 761-776.

Bonte, M., and P. De Clercq. 2008. Developmental and reproductive fitness of Orius laevigatus (Hemiptera: Anthocoridae) reared on factitious and artificial diets. J. Econ. Entomol. 101: 1127-1133.

Boyd, W. D., and D. R. Alverson. 2004. Effect of temperature and water source on development of Deraeocoris nebulosus (Uhler) (Heteroptera: Miridae), a predacious plant bug. J. Entomol. Sci. 39: 202-213.

Chambers, R. J., S. Long, and N. L. Helyer. 1993. Effectiveness of Orius laevigatus (Hemiptera: Anthocoridae) for the control of Frankliniella occidentalis on cucumber and pepper in the UK. Biocontrol Sci. Technol. 3: 295-307.

Crocker, G., and T. H. Day. 1987. An advantage to mate choice in the seaweed fly, Coelopa frigida. Behav. Ecol. Sociobiol. 20: 295-301.

De Clercq, P., and D. Degheele. 1997. Effects of mating status on body weight, oviposition, egg load, and predation in the predatory stinkbug Podisus maculiventris (Heteroptera: Pentatomidae). Ann. Entomol. Soc. Am. 90: 121-127.

De Clercq, P., Y. Arijs, T. Van Meir, G. Van Stappen, P. Sorgeloos, K. Dewettinck, M. Rey, S. Grenier, and G. Febvay. 2005. Nutritional value of brine shrimp cysts as a factitious food for Orius laevigatus (Heteroptera: Anthocoridae). Biocontrol Sci. Technol. 15: 467-479.

García-González, F., and L. W. Simmons. 2005. Sperm viability matters in insect sperm competition. Curr. Biol. 15: 271-275.

Gilliot, C. 2003. Male accessory gland secretions: modulators of female reproductive physiology and behavior. Annu. Rev. Entomol. 48: 163-184.

Grenier, S., and P. De Clercq. 2003. Comparison of artificially vs. naturally reared natural enemies and their potential for use in biological control, pp. 115-131. In J. C. van Lenteren (ed.), Quality control and the production of biological control agents: theory and testing procedures. CAB International, Wallingford, United Kingdom.

Gromko, M. H., M. E. Newport, and M. G. Kortier. 1984 Sperm dependence of female receptivity to remating in Drosophila melanogaster. Evolution 38: 1237-1282.

Hoikkala, A., J. Aspi, and L. Suvanto. 1998. Male courtship song frequency as an indicator of male genetic quality in an insect species, Drosophila montana. Proc. R. Soc. Lond. B Biol. 265: 503-508.

Ito, K., and T. Nakata. 1998. Effect of photoperiod on reproductive diapauses in the predatory bugs, Orius sauteri (Poppius) and O. minutus (Linnaeus) (Heteroptera: Anthocoridae). Appl. Entomol. Zool. 33: 115-120.

Jones, T. M., and M. A. Elgar. 2004. The role of male age, sperm age and mating history on fecundity and fertilization success in the hide beetle. Proc. R. Soc. Lond. B Biol. 271: 1311-1318.

Klowden, M. J. 1999. The check is in the male: male mosquitoes affect female physiology and behavior. Am. Mosq. Control Assoc. 15: 213-220.

Leon-Beck, M., and M. Coll. 2009. The mating system of the flower bug Orius laevigatus. Biol. Control 50: 199-203.

McNamara, K. B., T. M. Jones, and M. A. Elgar. 2004. Female reproductive status and mate choice in the hide beetle, Dermestes maculatus. J. Insect. Behav. 17: 337-352.

Mendes, S. M., V.H.P. Bueno, and C. M. Lívia. 2003. Influence of the presence/absence of males in the oviposition of Orius insidiosus (Say) (Hemiptera: Anthocoridae). IOBC WPRS Bull. 26: 143-146.

Montserrat, M., R. Albajes, and C. Castañé. 2000. Functional response of four heteropteran predators preying on greenhouse whitefly (Homoptera: Aleyrodidae) and Western flower thrips (Thysanoptera: Thripidae). Environ. Entomol. 29: 1075-1082.

Moore, A. J. 1994. Genetic evidence for the 'good genes' process of sexual selection. Behav. Ecol. Sociobiol. 35: 235-241.

Musolin, D. L., and K. Ito. 2008. Photoperiodic and temperature control of nymphal development and induction of reproductive diapause in two predatory Orius bugs: interspecific and geographic differences. Physiol. Entomol. 33: 291-301.

Musolin, D. L., K. Tsytsulina, and K. Ito. 2004. Photoperiodic and temperature control of reproductive diapause induction in the predatory bug Orius strigicollis (Heteroptera: Anthocoridae) and its implications for biological control. Biol. Control. 31: 91-98.

Nilakhe, S. S. 1977. Longevity and fecundity of female boll weevils placed with varying numbers of males. Ann. Entomol. Soc. Am. 70: 673-674.

Opp, S. B., and R. J. Prokopy. 1986. Variation in laboratory oviposition by Rhagoletis pomonella (Diptera: Tephritidae) in relation to mating status. Ann. Entomol. Soc. Am. 79: 705-710.

Partridge, L. 1980. Mate choice increases a component of offspring fitness in fruitflies. Nature 283: 290-291. 
Price, D. K., and T. F. Hansen. 1998. How does offspring quality change with age in male Drosophila melanogaster? Behav. Genet. 28: 395-402.

Rankin, S. M., V. A. TeBrugge, J. A. Murray, A. M. Schuler, and S. S. Tobe. 2009. Effects of selected neuropeptides, mating status and castration on male reproductive tract movements and immunolocalization of neuropeptides in earwigs. Comp. Biochem. Physiol. A 152: 83-90.

Riddick, E. 2009. Benefits and limitations of factitious prey and artificial diets on life parameters of predatory beetles, bugs, and lacewings: a mini-review. Biocontrol 54: 325339.

Rowe, L. 1994. The costs of mating and mate choice in water striders. Anim. Behav. 48: 1049-1056.

Sirot, L. K., S. L. Lapointe, R. Shatters, and M. Bausher. 2006. Transfer and fate of seminal fluid molecules in the beetle, Diaprepes abbreviates: implications for the reproductive biology of a pest species. J. Insect Physiol. 52: 300-308.

SPSS Inc. 2003. SPSS user's guide, version 12.0. SPSS Inc., Chicago, IL.

Tawfik, M.F.S., and A. M. Ata. 1973. The life-history of Orius laevigatus (Fieber). Bull. Soc. Entomol. Egypt 57: 145151.

Tram, U., and M. F. Wolfner. 1998. Seminal fluid regulation of female sexual attractiveness in Drosophila melanogaster. Proc. Natl. Acad. Sci. U.S.A. 95: 4051-4054. van Lenteren, J., A. Hale, J. N. Klapwijk, J. van Schelt, and S. Steinberg. 2003. Guidelines for quality control of commercially produced natural enemies, pp. 265-304. In J. C. van Lenteren [ed.], Quality control and production of biological control agents: theory and testing procedures. CAB International, Wallingford, United Kingdom.

Vandekerkhove, B., E. Van Baal, K. Bolckmans, and P. De Clercq. 2006. Effect of diet and mating status on ovarian development and oviposition in the polyphagous predator Macrolophus caliginosus (Heteroptera: Miridae). Biol. Control 39: 532-538.

Venzon, M., A. Janssen, and M. W. Sabelis. 2002. Prey preference and reproductive success of the generalist predator Orius laevigatus. Oikos 97: 116-124.

Watson, P. J., G. Arnqvist, and R. R. Stallman. 1998. Sexual conflict and the energetic costs of mating and mate choice in water striders. Am. Nat. 151: 46-58.

Watt, W. B., P. A. Carter, and K. Donohue. 1986. Females' choice of 'good genotypes' as mates is promoted by an insect mating system. Science (Wash., D.C.) 233: 11971190.

Yoshii, H., N. Tachi, R. Ohba, O. Sakamura, H. Takeyama, and T. Itani. 2001. Antihypertensive effect of ACE inhibitory oligopeptides from chicken egg yolks. Comp. Biochem. Physiol. C 128: 27-33.

Received 16 December 2009; accepted 28 March 2010. 